Check for updates

Cite this: RSC Adv., 2019, 9, 16797

\title{
Beneficial use of ultrasound irradiation in synthesis of beta-clinoptilolite composite used in heavy oil upgrading process
}

\begin{abstract}
Sahar Safari, ${ }^{a}$ Reza Khoshbin (D) ${ }^{\mathrm{b}}$ and Ramin Karimzadeh ${ }^{\star a}$
A novel beta-clinoptilolite composite was prepared from beta zeolite and alkaline treated clinoptilolite by employing conventional and sonicated mixing procedures. Parent and prepared catalysts were characterized by XRD, FE-SEM, $\mathrm{N}_{2}$ adsorption-desorption and $\mathrm{NH}_{3}-\mathrm{TPD}$ analyses. Prepared composite of beta zeolite and treated clinoptilolite exhibited improved structural properties especially upon sonicated mixing procedure. Employing ultrasound irradiation notably improved beta distribution in the composite and increased mesoporous volume and specific surface area from $0.245 \mathrm{~cm}^{3} \mathrm{~g}^{-1}$ and $171.3 \mathrm{~m}^{2} \mathrm{~g}^{-1}$ in conventionally mixed composite to $0.353 \mathrm{~cm}^{3} \mathrm{~g}^{-1}$ and $232.9 \mathrm{~m}^{2} \mathrm{~g}^{-1}$ in sonicated sample. Catalytic performance of prepared composite was evaluated in heavy oil upgrading process in a continuous fixed bed apparatus. Liquid product was specified by conducting SIMDIS-GC and GC/MS analyses. Spent catalysts were characterized by TGA, FTIR and XRD. Beta-clinoptilolite composite containing only $30 \mathrm{wt} \%$ of beta zeolite, exhibited similar performance to beta zeolite catalyst by resulting $75.3 \%$ viscosity reduction while producing lower amount of coke. Amount of light hydrocarbons produced over beta-clinoptilolite composite was $33.51 \mathrm{wt} \%$ while beta zeolite catalyst produced $35.58 \mathrm{wt} \%$ light hydrocarbons in upgrading process. Ultrasound irradiated composite showed more stable structure in catalytic cracking procedure compared to conventionally mixed composite. After $5 \mathrm{~h}$ time on stream, relative crystallinity of clinoptilolite phase in the conventionally mixed composite was reduced by $34.5 \%$ while sonicated sample remarkably preserved its structure during the reaction and only $1 \%$ reduction occurred for this sample.
\end{abstract}

\author{
Received 20th March 2019 \\ Accepted 21st May 2019 \\ DOI: 10.1039/c9ra02173f \\ rsc.li/rsc-advances
}

\section{Introduction}

Depletion of conventional and light oil resources and increasing demand for high-grade light fuels in recent decades have provided economic and strategic justifications to improve the methods and techniques of heavy oil upgrading processes. ${ }^{1}$ Among all the thermochemical methods employed so far, such as thermal cracking, catalytic cracking, hydrocracking and catalytic pyrolysis, ${ }^{2-4}$ catalytic cracking has been widely noticed in recent years due to the moderate operating conditions and controlled product distribution..$^{5-7}$

Zeolites are popular catalysts in oil processing and fuel production industries due to their crystalline aluminosilicate structure, acidity and shape selectivity. ${ }^{8}$ However, preparation and regeneration costs have always been matter of concern in industrial scale. Unlike synthetic zeolites, natural zeolites are found in mines and deposits in many parts of the world abundantly and have low prices. Natural zeolites may have lower external surfaces or non-homogenous phase and

${ }^{a}$ Faculty of Chemical Engineering, Tarbiat Modares University, P. O. Box 14115-114, Tehran, Islamic Republic of Iran.E-mail: ramin@modares.ac.ir

${ }^{b}$ Department of Chemical and Materials Engineering, Buein Zahra Technical University, Buein Zahra, Qazvin, Iran impurities but they have noticeable acidities. ${ }^{9}$ Clinoptilolite is one natural small pore zeolite widely used because of its cationexchange property and plentitude in nature. ${ }^{8}$ However, small pore size is one limitation for larger molecules such as heavy oils and lessens the rate of diffusion and mass transfer to the pores where active acidic sites are located. ${ }^{10}$ Presence of mesopores in zeolites alleviates the intracrystalline diffusion limitations and easier desorption of the products out of the structure takes place, resulting in more desired products due to the reduction of over cracking and secondary reactions. ${ }^{11}$ Different post treatment methods such as alkaline treatment and acid treatment have been widely employed to increase the porosity of different synthetic and natural zeolites by desilication and dealumination. ${ }^{\mathbf{1 2 - 1 6}}$ Lin et al. ${ }^{17}$ studied physicochemical properties of clinoptilolite modified by $\mathrm{NaOH}$ and found out that alkaline treatment increased the proportion of mesopores and cation exchange capacity of clinoptilolite. Beside alkaline treatment, further modifications may be conducted on treated clinoptilolite to induce even more improvements in catalytic cracking performance of this natural zeolite.

One of the modification techniques, which has been a subject of interest in recent years, is preparing composites of different zeolites such as ZSM-5/MCM-41, E-CAT/MCM-41, Y/ Beta, etc. ${ }^{18-23}$ These composites benefit from the advantageous 
features of different zeolites simultaneously. Zeolite beta is one of the zeolites numerously used in zeolite composites due to its moderate acidity and average pore size which makes it applicable in different petrochemical refinery processes such as alkylation, isomerization, methylation, esterification, cracking and etc. ${ }^{\mathbf{2 4 5}}$ Different composites of zeolite beta have been synthesized for different intentions, for example it has been used in beta/Y composite in order to benefit from larger pore openings of beta zeolite coupled with high acidity of $\mathrm{Y}$ zeolite, ${ }^{26,27}$ or in beta/MCM-41 composite to induce larger mesopore volume attained from mesoporous structure of MCM41 aluminosilicate paired with moderate acidity of zeolite beta. ${ }^{28-30}$ Therefore, beta zeolite has potential to be paired with different kinds of zeolites in a composite.

Zeolite composites may be synthesized by different methods such as crystallization process, seeding, hydrothermal synthesis, core shell structure, etc. ${ }^{30}$ However, these methods have many determining parameters such as temperature, alkaline environment, exact ratios of precursors and long synthesis times, which makes it difficult to have complete control over the synthesis procedure. Physical mixing is the easiest way to prepare a mixture of two zeolites. Although, result mixture may suffer from weak and nonhomogeneous dispersion. Particle dispersion in aqueous solutions is an important factor since particles are likely to aggregate together to form larger particles which affects different aspects such as stability and surface area. ${ }^{31,32}$ In order to achieve better distribution in the mixture ultrasound irradiation may be used in mixing procedure. As ultrasound wave passes through a liquid-solid medium explosion of micro bubbles (cavitation) occurs, resulting in formation of shock waves and hot spots with high temperatures and pressures which destroy particle agglomerations and cause a uniform distribution in medium. ${ }^{33,34}$ Positive effects of ultrasound irradiation on the dispersion level, size uniformity, decreased particle size, increased surface area and shortened preparation time on loading different materials on different supports such as zeolites have also been reported in the literature..$^{35-38}$ Sene et al..$^{39}$ investigated dispersion of $\mathrm{TiO}_{2}$ on clinoptilolite under low frequency probe type ultrasound irradiation. They concluded that ultrasound irradiation resulted in higher surface area and better distribution of $\mathrm{TiO}_{2}$ compared to conventional dispersion method.

The aim of this study is to develop a modification method to improve catalytic performance and structural stability of clinoptilolite in order to employ in heavy oil upgrading process. For this purpose, novel composite of alkaline treated clinoptilolite with beta zeolite was synthesized. Proposed composite benefits from low cost of natural zeolite and desirable catalytic performance of zeolite beta in light hydrocarbon production. Effect of ultrasound irradiation in physical mixing procedure was investigated to evaluate homogenous and stable dispersion compared to conventional mixing.

\section{Experimental section}

\subsection{Materials}

Beta zeolite $\left(\mathrm{SiO}_{2} / \mathrm{Al}_{2} \mathrm{O}_{3}=25\right)$ in ammonium form was purchased from Zeolyst International Company (CP814E). Raw
Iranian clinoptilolite was provided from Semnan deposits, in the northeast of Iran (Afrand Tuska Company). Raw materials used for treatments were sodium hydroxide $(\mathrm{NaOH})$ and ammonium nitrate $\left(\mathrm{NH}_{4} \mathrm{NO}_{3}\right)$ (Merck). A middle distillate cut used as feed in catalytic cracking experiments was provided from Arak Refinery.

\subsection{Catalyst preparation}

Beta zeolite was received in ammonium form, therefore, it was calcinated in furnace at $550{ }^{\circ} \mathrm{C}$ for $4 \mathrm{~h}$ in air stream in order to obtain protonated form of zeolite. This sample was labeled Beta. As received clinoptilolite zeolite was grinded to powder and sieved to particle size range of 100-250 $\mu \mathrm{m}$. Then it was ion exchanged and converted to protonated form twofold by 1 molar ammonium nitrate solution at $80^{\circ} \mathrm{C}$ for $4 \mathrm{~h}$, filtered, washed with deionized water, and dried in oven at $110^{\circ} \mathrm{C}$ over night. Finally, it was calcined at $550{ }^{\circ} \mathrm{C}$ for 4 hours in air stream. This sample was labeled CLT.

In order to perform alkaline treatment, clinoptilolite powder was treated with $1 \mathrm{M} \mathrm{NaOH}$ solution $\left(1 \mathrm{~g} / 40 \mathrm{~cm}^{3}\right)$ at $80^{\circ} \mathrm{C}$ for $2 \mathrm{~h}$. The suspension was immediately cooled down to room temperature in an ice-bath, filtered and washed until neutral $\mathrm{pH}$ was attained. The filtrate was dried in oven over night and then it was ion exchanged with ammonium nitrate solution as it was mentioned before. This sample was named AT-CLT.

Physical mixture of CLT and Beta was prepared by conventional mixing on a magnetically driven stirrer. 1 gram of CLT was mixed with adequate water and stirred for one hour in room temperature to make a homogenous suspension. Then, 0.4 gram of Beta sample was added to the mixture and stirred at $70{ }^{\circ} \mathrm{C}$ until total evaporation of water took place. The sample was dried in oven over night, calcinated at $550{ }^{\circ} \mathrm{C}$ for $4 \mathrm{~h}$ in air stream and labeled Beta/CLT.

Beta/AT-CLT sample was prepared likewise with AT-CLT sample instead of CLT sample.

Physical mixture of Beta and AT-CLT was also prepared under ultrasound irradiation using a UP400S apparatus (Hielscher, Germany) with $20 \mathrm{~mm}$ probe diameter. 1 gram of ATCLT sample was mixed with adequate water and stirred for one hour in room temperature to make a homogenous suspension. Then, 0.4 gram of Beta sample was added to the mixture and slurry was exposed to ultrasound irradiation with $250 \mathrm{~W}$ power and $20 \mathrm{kHz}$ frequency for 30 minutes in room temperature. Then it was dried in oven over night, calcinated at $550{ }^{\circ} \mathrm{C}$ for $4 \mathrm{~h}$ in air stream and referred to as US-Beta/AT-CLT. Composite preparation procedure is schematically illustrated in Fig. 1.

\subsection{Catalyst characterization}

Crystallinity and phase purity of samples were evaluated by XRD analysis carried out by using an X'Pert PRO MPD diffractometer (Philips, Netherland) using $\mathrm{Cu} \mathrm{K} \alpha$ radiation $(\lambda=0.15405 \AA)$ at $40 \mathrm{kV}$ and $30 \mathrm{~mA}$ in scanned angle range of 5-60 with $0.02^{\circ} \mathrm{s}^{-1}$ step size. Samples were strewed on Zero Background Silicon Holder placed on PW1812 sample holders (both Philips).

Relative crystallinity values of modified samples were determined based on the intensity of main characteristic diffraction picks of parent samples. 


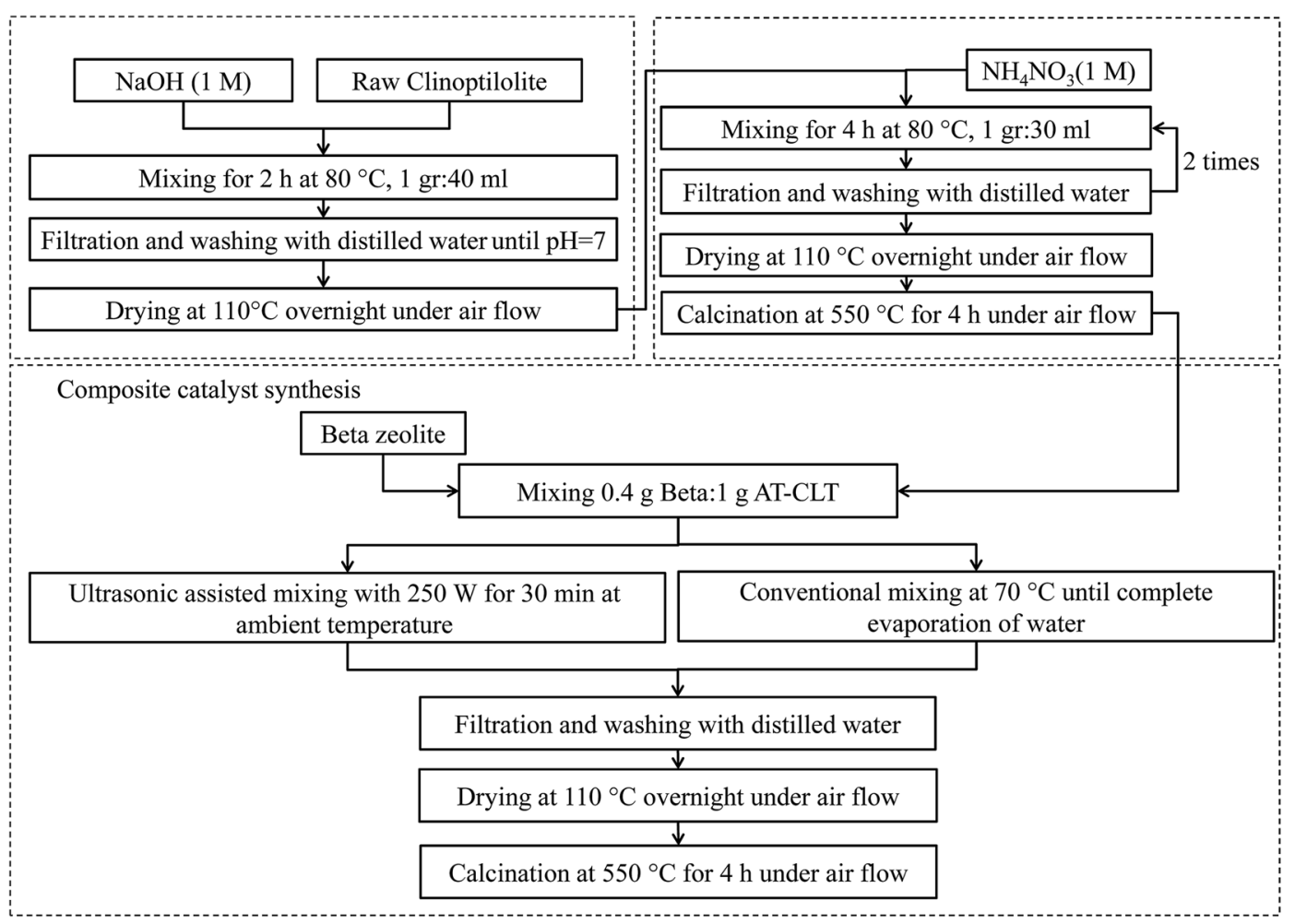

Fig. 1 Schematic flow chart of composite preparation procedure.

Nitrogen sorption isotherms were recorded by an ASAP 2020 V3.03 G Plus (Micromeritics, Norcross, Georgia, USA) instrument at $77 \mathrm{~K}$ in order to evaluate the structural and surface characteristics of the samples. Before the measurement, samples were degassed for $2 \mathrm{~h}$ at $200{ }^{\circ} \mathrm{C}$. The specific surface areas of the obtained samples were calculated by the BrunauerEmmett-Teller (BET) method, pore size distribution and volume of mesopores were determined by using Barrett-JoynerHalenda (BJH) method derived from the nitrogen desorption isotherm and $t$-plot method was used to calculate the external surface area and micropore surface area and volume of micropores.

FE-SEM observations using Scanning Electron Microscope S4160 (HITACHI, Japan) apparatus were carried out in order to examine the morphologies of samples.

Surface acidity of the samples was evaluated by temperature programmed desorption of ammonia ( $\mathrm{NH}_{3}$-TPD) using a BELCAT-A apparatus (MicrotracBEL, Japan) equipped with a TCD. $0.2 \mathrm{~g}$ of each sample was pretreated at $550^{\circ} \mathrm{C}$ for 2 hours under He flow. Then it was cooled down to $200^{\circ} \mathrm{C}$ and stripped for 10 minutes. Adsorption took place in a gas stream of $\mathrm{NH}_{3} / \mathrm{He}(50$ $\mathrm{cm}^{3} \mathrm{~min}^{-1}, 2.5 \mathrm{wt} \%$ of $\mathrm{NH}_{3}$ ) for 30 minutes followed by $0.5 \mathrm{~h}$ stripping to remove the weakly adsorbed amount of $\mathrm{NH}_{3}$. Temperature was then elevated to $1123 \mathrm{~K}$ with a $10 \mathrm{~K} \mathrm{~min}^{-1}$ ramp in a $50 \mathrm{~cm}^{3} \mathrm{~min}^{-1}$ He stream for desorption of $\mathrm{NH}_{3}$ molecules.

Changes in crystalline structure of spent catalysts after the process were studied from XRD analysis in order to investigate their stability. Spent catalysts were also examined with a SDT Q600 V20.9 Build 20 thermal gravimetric (TA Instruments, New
Castle, DE, USA) to determine amount of coke deposited on their surfaces through thermogravimetric analysis. For this purpose, changes in samples weight were recorded during the rising of temperature from ambient temperature to $800{ }^{\circ} \mathrm{C}$ by a $10{ }^{\circ} \mathrm{C} \min ^{-1}$ ramp. FTIR spectra of spent catalysts were recorded by IR spectrometer (PerkinElmer spectrophotometer version 10.03.06, USA) using the potassium bromide $(\mathrm{KBr})$ pressed disk technique in order to examine the type of coke deposited on the catalyst.

\subsection{Catalyst performance test}

The experimental apparatus used for catalytic cracking test is shown in Fig. 2. Tests were performed in a continuous down flow fixed bed reactor made from stainless steel in $10 \mathrm{~mm}$ internal diameter, which was placed in a conventional furnace to provide the reaction temperature. A thermocouple placed on the reactor outer surface was applied to monitor the furnace temperature.

Prepared catalysts were shaped into pellets and reactor was loaded with 1 gram of catalyst sample placed between two pieces of quartz wool in the middle of the reactor. Temperature of catalyst bed was monitored using a K-type thermocouple inserted in the middle of the catalyst bed. A middle distillate cut with specifications listed in Table 1 provided from Arak refinery was used as feed. Nitrogen stream as carrier gas was mixed with feed, which was injected via syringe pump and were preheated up to $350^{\circ} \mathrm{C}$ in the stream line before entering the reactor. The feed streamline has a by-pass valve before the reactor inlet. After starting the injection with syringe pump, adequate time was considered for feed stream to become steady. When the exiting 


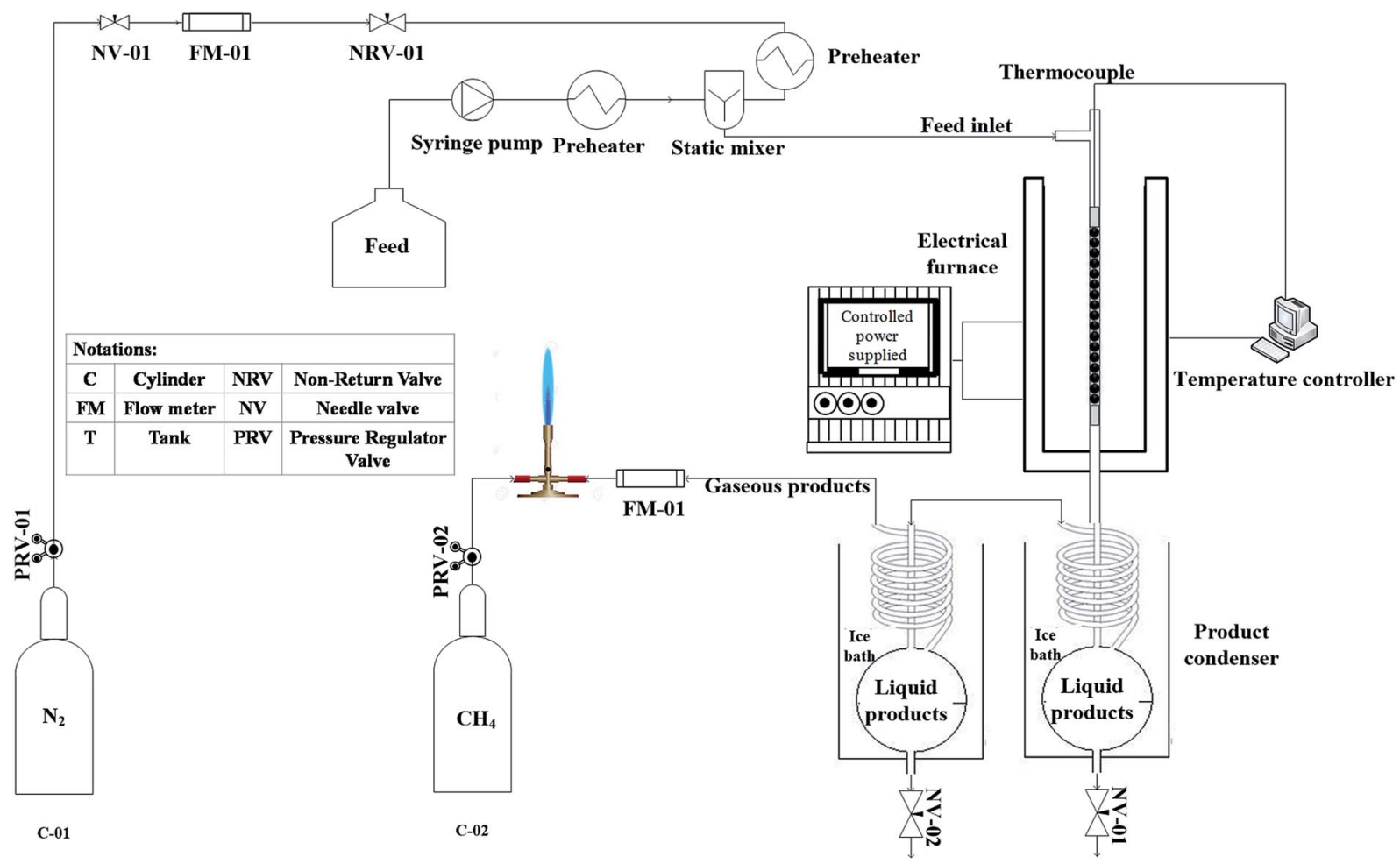

Fig. 2 Schematic diagram of experimental apparatus for heavy oil cracking over beta-clinoptilolite physical composites.

flow rate of by pass stream became steady, the valve was closed and feed was directed to the reactor. Reactions were conducted at atmospheric pressure and $550{ }^{\circ} \mathrm{C}$. Before the feed injection, reactor was purged with $50 \mathrm{~cm}^{3} \mathrm{~min}^{-1}$ nitrogen flow while bed temperature was elevated to $550{ }^{\circ} \mathrm{C}$ with a $10{ }^{\circ} \mathrm{C} \mathrm{min}{ }^{-1} \mathrm{ramp}$. When desired temperature was reached, feed flow with WHSV $=$ $32 \mathrm{~h}^{-1}$ was injected into the reactor.

At the reactor outlet, exiting liquid product was led to a twostage condenser and condensable products were collected. Exiting non-condensable gas products were measured in a flow meter and then burned in flare. Amounts of liquid product and volume of gas flow were recorded every 30 minutes. Amount of feed inverted to coke was determined by TGA analysis and amount of gas product was determined by mass balance. Yield of each product was calculated by following equations:

$$
\begin{aligned}
\text { Liquid product yield }\left(Y_{\text {liquid }}\right)= & \frac{\text { weight of liquid product }}{\text { weight of feed }} \\
& \times 100
\end{aligned}
$$

Table 1 Feedstock properties

\begin{tabular}{ll}
\hline Characteristic & Value \\
\hline Viscosity $(\mathrm{cSt})$ & 6.64 \\
Density $\left(\mathrm{g} \mathrm{cm}^{-3}\right)$ & 0.838 \\
Refractive index & 1.46 \\
Total sulphur $(\mathrm{ppm})$ & 80 \\
IBP $\left({ }^{\circ} \mathrm{C}\right)$ & 294 \\
FBP $\left({ }^{\circ} \mathrm{C}\right)$ & 488
\end{tabular}

$$
\text { Coke yield }\left(Y_{\text {coke }}\right)=\frac{\text { weight of coke }}{\text { weight of feed }} \times 100
$$

Gas product yield $\left(Y_{\text {gas }}\right)$

$=\frac{\text { weight of feed }- \text { weight of liquid product }- \text { weight of coke }}{\text { weight of feed }}$

$\times 100$

The process was on going for 300 minutes in order to evaluate the stability of catalyst and then feed stream was stopped and nitrogen gas passed through the reactor for one more hour to purge the catalyst bed and take out the remaining hydrocarbons.

Collected liquid product was analyzed by a gas chromatograph-mass spectrometer, GC/MS, (Agilent 6890N/ 5973 Network Mass Selective Detector) equipped with a HP-1 Agilent column with dimensions measuring $30 \mathrm{~m} \times 0.25 \mathrm{~mm}$ $\times 0.5 \mu \mathrm{m}$. The oven was programmed to be held at $50{ }^{\circ} \mathrm{C}$ for $2 \mathrm{~min}$, followed by a temperature elevation to $300{ }^{\circ} \mathrm{C}$ with $8{ }^{\circ} \mathrm{C} \mathrm{min}{ }^{-1}$ ramping and then held for $10 \mathrm{~min}$. The injection volume was $0.2 \mu \mathrm{l}$ with split ratio equal to $1: 50$ and injector temperature of $320^{\circ} \mathrm{C}$. The unknown compounds were identified by finding the matches of their retention times and MS spectra in the National Institute of Standards and Technology (NIST) library. ${ }^{40}$ Liquid product was also analyzed using a simulated distillation GC analyzer (Agilent, USA) equipped 
with flame ionization detector (FID) and a DB-2887 capillary column $(10 \mathrm{~m} \times 530 \mu \mathrm{m})$ based on ASTM D2887 standard method. Containing hydrocarbons were classified as three cuts based on boiling point ranges: naphtha + kerosene $\left(30-250{ }^{\circ} \mathrm{C}\right)$, diesel $\left(250-370{ }^{\circ} \mathrm{C}\right)$ and heavy oil $\left(370{ }^{\circ} \mathrm{C}+\right)$. Conversion was calculated from below equation:

Physical properties of liquid product such as density, refractive index (RI) and viscosity were also measured after the collection. Density was measured by using a $10 \mathrm{ml}$ pycnometer (Isolab, Germany) at $20{ }^{\circ} \mathrm{C}$ based on ASTM D1480. Abbe Refractometer NAR-1T Liquid (Atago, Japan) was used for determining refractive index of liquid product as specified by ASTM D1218. occur and selective dissolution of silicon takes place, ${ }^{\mathbf{1 7}}$ therefore, only slight decrease in crystallinity is observed. Calculated relative crystallinities are presented in Table 2.

XRD pattern of Beta sample presents typical diffraction pattern of zeolite beta with detected peaks at $2 \theta=7.5$ and 22.4 (JCPDS 48-0074).

Beta/CLT sample XRD pattern displays both crystalline phases of clinoptilolite and beta zeolite indicating the coexistence of both phases in the physical mixture of beta and clinoptilolite, meanwhile, no new peak is observed. Intensities of all the peaks have decreased compared to their parents, CLT and Beta, which is in line with results of Gao et al. ${ }^{30}$ in which, diffraction peaks have lower intensities after making a physical mixture of Beta-MCM-41.

$$
\text { Conversion }=\frac{\text { weight of heavy oil cut in the feed }- \text { weight of heavy oil cut in the product }}{\text { weight of heavy oil cut in the feed }} \times 100
$$

Kinematic viscosity of the liquid product was measured by a Cannon Fenske Opaque Liquid viscometer, size 75 (Normalab, France) used in a hot bath according to ASTM D445 standard which consists in measuring the time for a volume of liquid to flow under gravity through a calibrated glass capillary viscometer in certain temperature.

\section{Results and discussion}

\subsection{Characterization of prepared catalysts}

3.1.1. XRD analysis. X-ray diffraction patterns of parent and treated samples are presented in Fig. 3. Raw clinoptilolite sample has shown the typical diffraction peaks of clinoptilolite zeolite structure. Diffraction peaks observed at $2 \theta=9.8,11.2$, $13.3,17.3,19.1,22.7,26.1,28.2,28.5,30.2,31.9,32.8$ are assigned to clinoptilolite (00-025-1349 JCPDS card).

After performing ion exchange treatment, peak intensities have increased for CLT sample. Natural zeolite is a mineral extracted from deposits with slight impurities and dust. After two time ion exchange and filtration and washing with distilled water for several times the impurities are removed and peak intensities and crystallinity of clinoptilolite has increased which is in line with former reports. ${ }^{\mathbf{1 4 4 1}}$ This increment in the crystallinity for CLT sample compared to raw clinoptilolite may also be due to the replacement of the metal cations of natural zeolite by protons $\left(\mathrm{H}^{+}\right) .{ }^{41}$

A slight decrease in peak intensities was observed for AT-CLT and crystalline structure was preserved after alkaline treatment. Silicon extraction from zeolite structure takes place during alkaline treatment of a zeolite as have been revealed numerously in literature so far, which in turn results in a more open structure and mesoporosity. ${ }^{\mathbf{4 2 - 4 4}}$ The $\mathrm{OH}^{-}$present in alkali solution attacks the zeolite structure but since clinoptilolite is negatively charged and silicon atoms are preserved with neighboring four ligand $\mathrm{Al}$ atoms, framework damage does not
Ultrasound irradiation has affected the crystalline structure of treated physical mixture sample compared to Beta/AT-CLT sample. Intensities of all the peaks have decreased for USBeta/AT-CLT sample compared to Beta/AT-CLT sample but crystalline structure is conserved. It has been reported in the literature that reduction in relative crystallinity in the presence of ultrasound irradiation can be ascribed to improvement of active phase dispersion over the catalyst support. ${ }^{38,39,45}$ Explosion of cavitation bubbles results in formation of microjets in solid-liquid interface, which suppress the formation of agglomeration on the support surface. In other words, higher level of dispersion is achievable by increment of micromixing and creation of harsh agitations due to the employing ultrasound during catalyst synthesis. ${ }^{46}$

3.1.2. BET analysis. Textural properties of prepared samples were evaluated by $\mathrm{N}_{2}$ adsorption-desorption analysis at $77 \mathrm{~K}$. The adsorption-desorption isotherms and BJH pore size distributions are displayed in Fig. 4 and 5 respectively. Calculated textural properties are presented in Table 3.

Beta sample shows a typical type IV isotherm with $\mathrm{H}-3$ type hysteresis loop at high relative pressures, indicating on presence of slit mesoporous structure. ${ }^{25}$ Extracted data from $\mathrm{N}_{2}$ adsorption-desorption analysis by BET method reveals that Beta sample has a very high surface area $\left(708.9 \mathrm{~m}^{2} \mathrm{~g}^{-1}\right)$ and large total pore volume $\left(0.94 \mathrm{~cm}^{3} \mathrm{~g}^{-1}\right)$. Micropore area and micropore volume derived from the adsorption isotherm by means of $t$-plot method are equal to $252.6 \mathrm{~m}^{2} \mathrm{~g}^{-1}$ and $0.21 \mathrm{~cm}^{3}$ $\mathrm{g}^{-1}$ respectively.

Results revealed that alkaline treatment has notably influenced porous structure of clinoptilolite. Ion exchanged clinoptilolite sample (CLT) and alkaline treated sample (AT-CLT), have shown type II isotherms attributed to unrestricted monolayer-multilayer adsorption material with hysteresis type 3 , which is associated with the filling and emptying of 


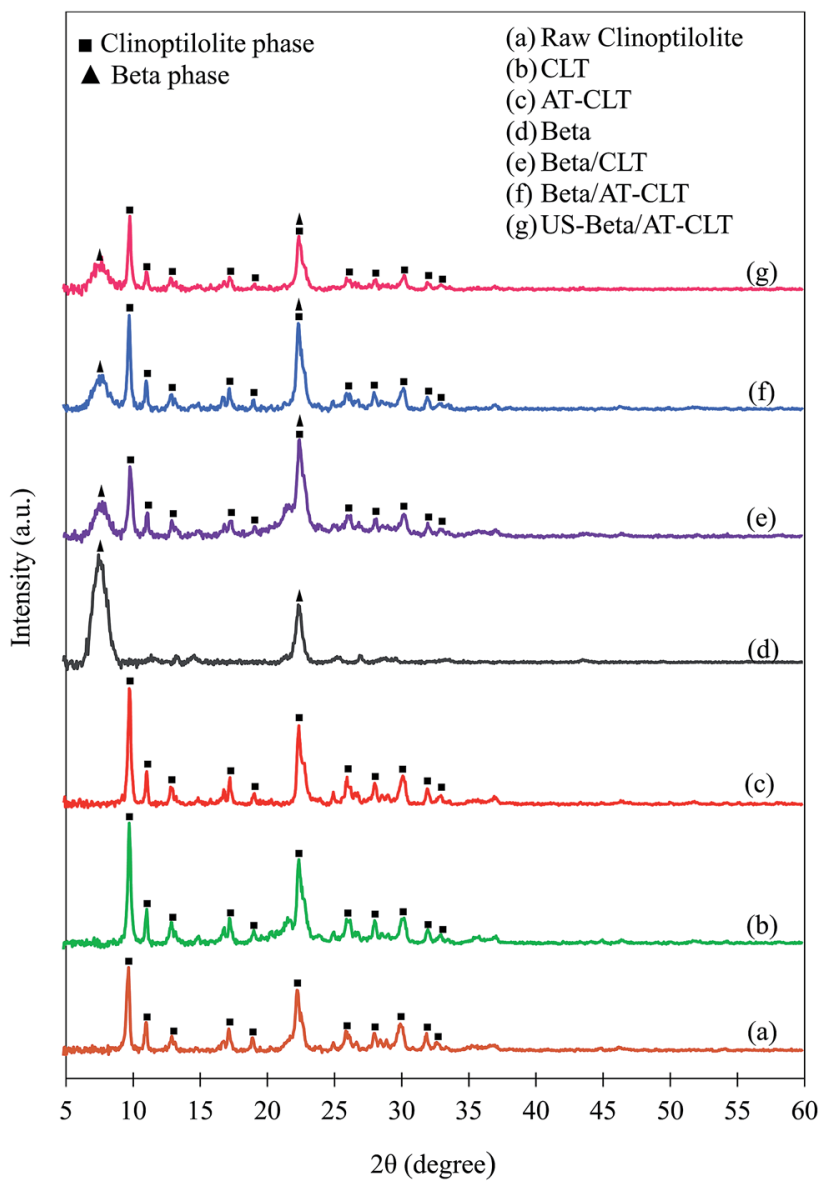

Fig. 3 XRD patterns of (a) raw clinoptilolite and treated samples: (b) CLT, (c) AT-CLT, (d) Beta, (e) Beta/CLT, (f) Beta/AT-CLT, (g) US-Beta/ AT-CLT ( $\Delta$ Beta phase, $\mathbf{\square}$ clinoptilolite phase).

mesopores. CLT sample and AT-CLT samples have similar isotherms at low relative pressure, but at higher pressures, the quantity adsorbed is larger on AT-CLT, which is explained by larger total pore volume of the latter. Alkaline treatment increased total pore volume of CLT by $77.8 \%$. Microporous volume and mesoporous volume were increased by $16 \%$ and $83 \%$ respectively. These improved textural properties which are consistent with results of previous researches, ${ }^{17,47}$ arise from silicon extraction from zeolite structure which results in creation of voids and increment of pore volumes and external

Table 2 Relative crystallinities of fresh and spent catalysts

\begin{tabular}{llllll}
\hline & \multicolumn{2}{l}{$\begin{array}{l}\text { Fresh catalyst relative } \\
\text { crystallinity (\%) }\end{array}$} & & \multicolumn{2}{l}{$\begin{array}{l}\text { Spent catalyst relative } \\
\text { crystallinity (\%) }\end{array}$} \\
\cline { 2 - 3 } Sample name & Clinoptilolite & Beta & & Clinoptilolite & Beta \\
\hline CLT & 100 & - & & 82.8 & - \\
AT-CLT & 92.6 & - & & 76.6 & - \\
Beta & - & 100 & & - & 100 \\
Beta/CLT & 69.5 & 53.8 & & 55.8 & 41.4 \\
Beta/AT-CLT & 85.2 & 52.2 & & 55.8 & 35.9 \\
US-Beta/AT-CLT & 49.2 & 37.5 & & 48.4 & 33.7
\end{tabular}

surface area. ${ }^{17}$ It has been demonstrated in literature that sever silicon extraction may destroy micropore channels of zeolite structure, hence microporous volume decreases. ${ }^{34}$ Increase in micropore volume during alkaline treatment proves that moderate conditions of alkaline treatment have been applied which is in line with XRD results. Since active sites are located in micropores it is an advantage that alkaline treatment has successfully improved both microporous and mesoporous volumes.

Physical mixture of Beta and CLT, Beta/CLT with $30 \mathrm{wt} \%$ of Beta, presents higher surface area as well as pore volume compared to CLT sample. BET surface area has increased to $170.6 \mathrm{~m}^{2} \mathrm{~g}^{-1}$ and microporous and mesoporous volumes have notably increased to $0.046 \mathrm{~cm}^{3} \mathrm{~g}^{-1}$ and $0.214 \mathrm{~cm}^{3} \mathrm{~g}^{-1}$ respectively. Distributed Beta particles in the mixture are the reason of these textural improvements. Adsorption isotherm of Beta/CLT is attributed to materials containing both micropores and mesopores and can be classified as type II with hysteresis evidencing presence of mesoporous structure and compared to CLT sample has much higher $\mathrm{N}_{2}$ adsorption at high relative pressures.

Beta/AT-CLT has presented similar isotherm with higher uptakes compared to Beta/CLT at high relative pressures, which regards to higher mesopore volume of Beta/AT-CLT resulting in higher adsorbed quantity. These physically mixed samples, show larger hysteresis loops and higher $\mathrm{N}_{2}$ uptakes due to the presence of Beta distributed in the mixtures, which results in more mesoporosity and internal voids.

Physical mixture of Beta and AT-CLT sample prepared under ultrasound irradiation, US-Beta/AT-CLT, has notable superiorities in textural properties compared to Beta/AT-CLT. Applying ultrasound irradiation during mixing improved specific surface area, micropore surface area and mesopore volume by $34 \%$, $36 \%$ and $44 \%$ respectively while the treatment took place in shorter time and was conducted in room temperature compared to conventional mixing method.

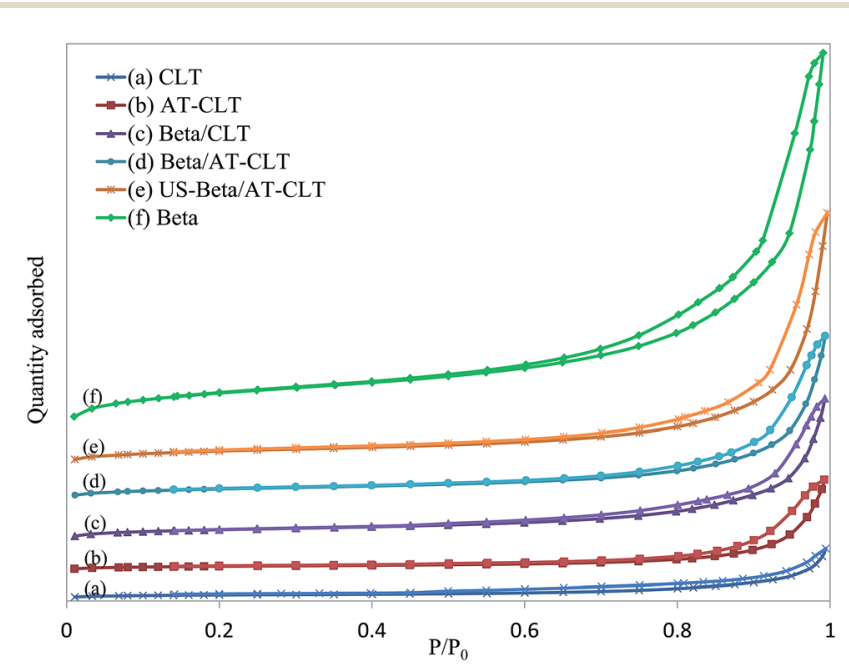

Fig. 4 Nitrogen adsorption-desorption isotherms for prepared samples: (a) CLT, (b) AT-CLT, (c) Beta/CLT, (d) Beta/AT-CLT, (e) USBeta/AT-CLT, (f) Beta. 


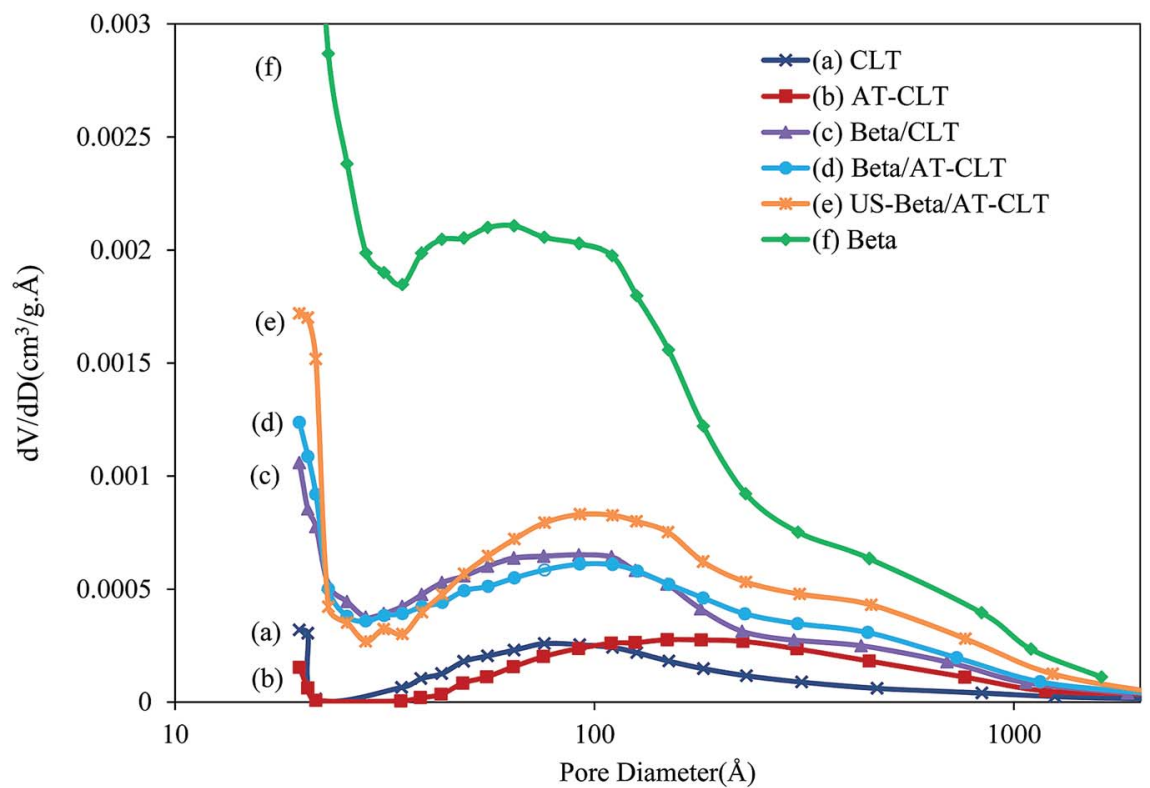

Fig. 5 BJH pore size distribution of treated samples: (a) CLT, (b) AT-CLT, (c) Beta/CLT, (d) Beta/AT-CLT, (e) US-Beta/AT-CLT, (f) Beta.

It has been previously revealed in the literature that ultrasound irradiation has a positive effect on particle distribution in aqueous media..$^{35-38}$ During conventional mixing pore plugging and agglomeration of surface particles occur. These problems are partially solved under sonication due to the induced agitations by microjets. ${ }^{39}$ Better distribution of Beta in physical mixture has led to increment of specific surface area and pore volume.

The BJH pore size distributions of the samples are displayed in Fig. 5. Beta presents two peaks around $10 \mathrm{~nm}$ and $100 \mathrm{~nm}$ with narrower distribution around $10 \mathrm{~nm}$. The relating pattern for Beta evidences the presence of high amount of mesopores with pore diameter sizes approximately around $10 \mathrm{~nm}$ in this sample. CLT diagram exhibits one peak around $10 \mathrm{~nm}$ with much smaller pore volume compared to Beta. After alkaline treatment, noticeable shift of the diagram to larger pore diameters around $100 \mathrm{~nm}$ has occurred for AT-CLT sample. This phenomena is in line with results of Wang et al. ${ }^{48}$ who observed pore size increment after performing alkaline treatment on clinoptilolite and attributed this to desilication.

Distribution pattern of Beta/CLT presents two peaks similar to Beta sample. Pores with diameters around $100 \mathrm{~nm}$ in the composite, come from Beta particles distributed in the mixture, however with lower pore volume amounts compared to Beta sample. Duan et al. ${ }^{29}$ observed similar results in preparing betaMCM-48 composite.

Pattern of US-Beta/AT-CLT is clearly more similar to Beta sample with more centralized pore size distribution around $10 \mathrm{~nm}$ and $100 \mathrm{~nm}$, compared to Beta/AT-CLT. These results clearly demonstrate that Beta has been dispersed more uniformly in the composite under sonication exhibiting higher number of pores as well as narrower size distributions. ${ }^{49}$

3.1.3. FE-SEM analysis. Morphologies of treated samples and particle distribution in physical mixtures are shown by SEM pictures displayed in Fig. 6. As can be seen all the samples have nanometric surface particles which provide more active sites for catalytic activity. Beta sample (Fig. 6(a)) presents the typical morphological status of zeolite beta with discrete particles mostly in ellipsoid or spherical shapes with roughly uniform particle sizes and some aggregations with irregular shapes as reported in literature. ${ }^{50}$ Similar to the previous reports on clinoptilolite morphology, congregated plates of different dimensions for CLT sample are observable in Fig. 6(b) while partial surface roughening for alkali treated sample has occurred

Table 3 Textural properties of treated samples obtained from $\mathrm{N}_{2}$ adsorption-desorption analysis

\begin{tabular}{|c|c|c|c|c|c|c|}
\hline Sample & $S_{\mathrm{BET}}\left(\mathrm{m}^{2} \mathrm{~g}^{-1}\right)$ & $S_{\mathrm{EXT}}{ }^{a}\left(\mathrm{~m}^{2} \mathrm{~g}^{-1}\right)$ & $S_{\mathrm{mic}}^{b}\left(\mathrm{~m}^{2} \mathrm{~g}^{-1}\right)$ & $V_{\mathrm{t}}^{c}\left(\mathrm{~cm}^{3} \mathrm{~g}^{-1}\right)$ & $V_{\text {mic }}{ }^{d}\left(\mathrm{~cm}^{3} \mathrm{~g}^{-1}\right)$ & $V_{\text {meso }}^{e}\left(\mathrm{~cm}^{3} \mathrm{~g}^{-1}\right)$ \\
\hline Beta & 708.9 & 252.6 & 456.4 & 0.943 & 0.210 & 0.733 \\
\hline CLT & 34.5 & 21.1 & 13.4 & 0.081 & 0.006 & 0.075 \\
\hline Beta/CLT & 170.6 & 69.1 & 101.5 & 0.260 & 0.046 & 0.214 \\
\hline Beta/AT-CLT & 171.3 & 72.2 & 99.1 & 0.290 & 0.045 & 0.245 \\
\hline US-Beta/AT-CLT & 232.9 & 97.9 & 135 & 0.415 & 0.062 & 0.353 \\
\hline
\end{tabular}

${ }^{a} t$-Plot external surface area. ${ }^{b} t$-Plot micropore surface area. ${ }^{c}$ Volume adsorbed at $P / P_{0}=0.99 .{ }^{d} t$-Plot micropore volume. ${ }^{e}$ Mesopore volume $\left(V_{\text {total }}\right.$ $\left.-V_{\text {micro }}\right)$. 

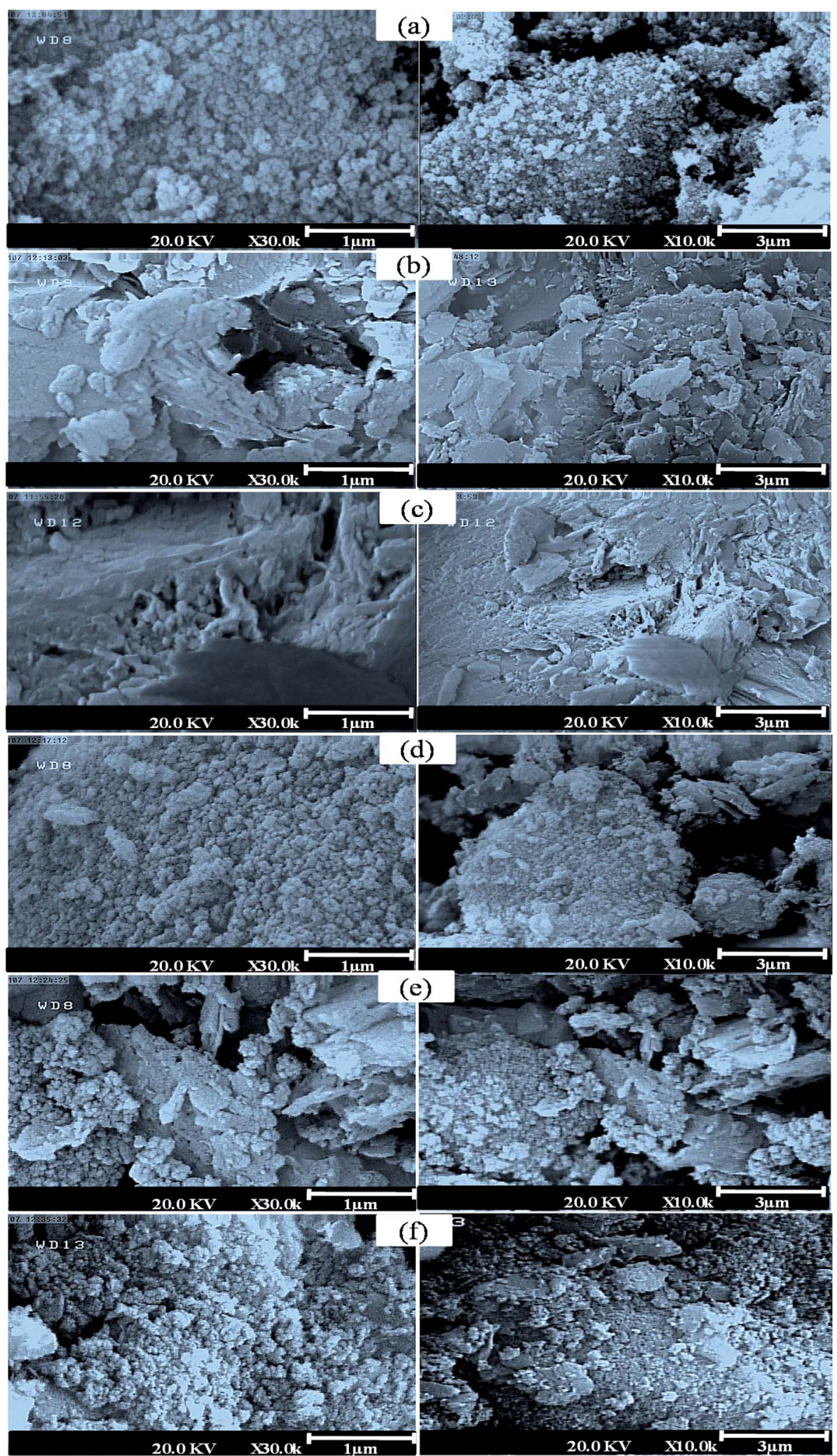

Fig. 6 SEM pictures of prepared samples, (a) Beta, (b) CLT, (c) AT-CLT, (d) Beta/CLT, (e) Beta/AT-CLT, (f) US-Beta/AT-CLT.

according to Fig. 6(c) which is consistent with previous observations. $^{8,51,52}$ Alkaline treatment causes desilication, which results in partial destruction of crystals and more open morphology. ${ }^{17}$
Fig. 6(d) shows nanometric particles of Beta with different shapes distributed on plates of CLT in Beta/CLT sample. Aggregates of Beta particles on the surface are observable which indicates nonhomogeneous distribution of Beta on CLT 
sample. Minor morphological differences are observed between this sample and Beta/AT-CLT sample (Fig. 6(e)).

However, SEM pictures of US-Beta/AT-CLT shown in Fig. 6(f) compared to Beta/AT-CLT reveal that ultrasound irradiation has affected the distribution of Beta particles on AT-CLT surface. Better surface coverage and more homogenous distribution with less aggregate formation are achieved by using ultrasound irradiation. Explosion of cavitation bubbles formed during sonication causes shock waves which push the aggregated particles on the external surface, smashing them and leading them to penetrate into the pores and forming smaller particles. ${ }^{39,53}$ Some fine particles are observed in this sample, which is a result of harsh environment of sonicated mixing.

3.1.4. $\mathbf{N H}_{3}$-TPD analysis. Fig. 7 displays the results of $\mathrm{NH}_{3}$ temperature programmed desorption of prepared samples. All the samples have shown three peaks presenting three kinds of acidic sites. Peaks observed under $250{ }^{\circ} \mathrm{C}$ are attributed to ammonia adsorbed on weak acid sites and peaks observed over $400{ }^{\circ} \mathrm{C}$ are attributed to the desorption of strongly adsorbed $\mathrm{NH}_{3}$ molecules on strong acid sites. Peaks located between these regions are assigned to moderate-strong acidic sites in the samples. ${ }^{30}$ Different values of acidities for each sample, based on the amount of desorbed ammonia were calculated from desorption peak areas and are presented in Table 4.

According to the patterns obtained for CLT and Beta samples these two zeolites have different intrinsic acidic properties.

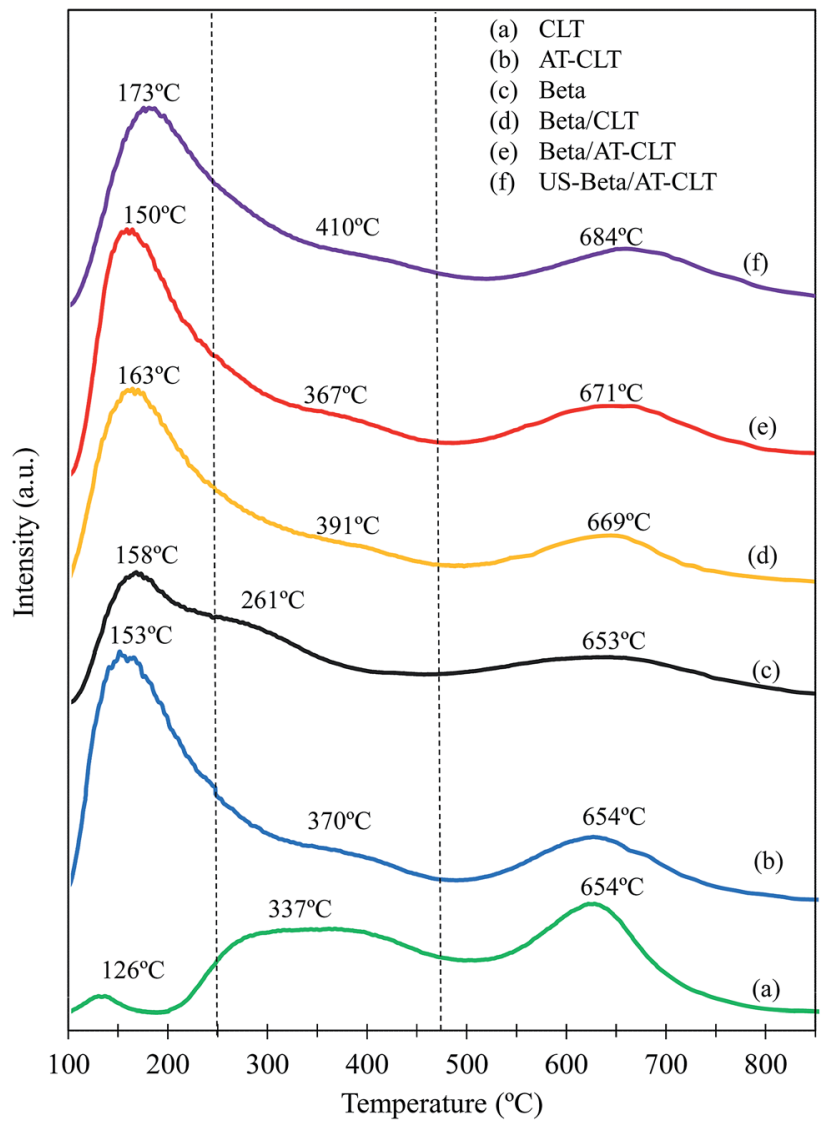

Fig. $7 \mathrm{NH}_{3}$-TPD spectra of prepared samples: (a) CLT, (b) AT-CLT, (c) Beta, (d) Beta/CLT, (e) Beta/AT-CLT, (f) US-Beta/AT-CLT.
Ammonia desorption profile for Beta zeolite indicates on the presence of weak, medium and strong acidity, which is compatible with results revealed elsewhere. ${ }^{29,50}$ High concentration of weak and moderate acidic sites on Beta, which prevents over cracking of products and reactants, is the reason of higher selectivity of this zeolite to intermediate cracking products in heavy oil upgrading. ${ }^{30}$ CLT sample has also three distinct peaks at $126{ }^{\circ} \mathrm{C}, 337{ }^{\circ} \mathrm{C}$ and $654^{\circ} \mathrm{C}$. It has been proposed that high temperature peak is associated to the framework $\mathrm{Al}$ atoms which induce strong acidity, while low temperature peak represents weak acid sites ascribed to nonframework $\mathrm{Al}$ atoms. ${ }^{54,55}$ Natural zeolite used in this research has a $\mathrm{Si} / \mathrm{Al}$ ratio equal to 5.66 , which indicates the presence of high amount of framework $\mathrm{Al}$ atoms inducing strong acidity in the zeolite. Total acidity of Beta is larger than CLT due to the higher amounts of weak and medium-strong acid sites present in the Beta sample.

After conducting alkaline treatment on clinoptilolite, amount of weak acid sites has extremely increased for AT-CLT sample in expense of strong acid sites. Li et al. ${ }^{56}$ observed similar results after ZSM-5 alkaline treatment and it was demonstrated that transformation of strong Brønsted acid sites to Lewis acid sites which have weaker acidity strength, is attributed to the $\mathrm{Si}-\mathrm{OH}$ sites removal due to the desilication and relocating of extracted $\mathrm{Al}$ atom sites on external surface of the zeolite and changing into non-framework $\mathrm{Al}$ atoms. ${ }^{56}$ Temperature of desorption for weak and moderate acid sites on AT-CLT sample are slightly higher than that of CLT sample $\left(154^{\circ} \mathrm{C}\right.$ and $\left.370{ }^{\circ} \mathrm{C}\right)$. Therefore, one can say these acid sites are slightly stronger than those on CLT sample. ${ }^{55}$

Beta/AT-CLT sample presented higher acidity compared to Beta/CLT. All three kinds of acidic sites possess higher amounts compared to Beta/CLT since alkaline treatment extremely increased the acidity of clinoptilolite. US-Beta/AT-CLT exhibits slightly lower acidity compared to Beta/AT-CLT which may be due to the lower crystallinity of prepared composite under ultrasound irradiation which is in agreement with results of XRD analysis for this sample.

\subsection{Catalytic performances of prepared samples in heavy oil upgrading process}

In order to investigate and compare the catalytic performances of different prepared samples in upgrading of heavy oil, continuous fixed bed catalytic cracking of heavy oil feed was conducted for each sample according to the procedure explained in Section 2.4. Catalytic activity was evaluated based on the yield of liquid product after $5 \mathrm{~h}$ time on stream and liquid product quality for each sample. In addition, TGA, FTIR and XRD analysis of spent catalyst were studied after the process.

3.2.1. Catalytic activity. In heavy oil cracking processes, gas production is a sign of catalytic activity and production of lighter hydrocarbons. As the time on stream increases, the catalytic activity faces deterioration due to the coke formation or structural damages caused by process conditions such as temperature. ${ }^{57}$ Therefore, gas production decreases after 
Table 4 Acidic properties of prepared samples obtained from $\mathrm{NH}_{3}-\mathrm{TPD}_{\text {analysis }}{ }^{a}$

\begin{tabular}{lllll}
\hline Samples & $A_{\mathrm{T}}\left(\mathrm{mmol} \mathrm{g}^{-1}\right)$ & $A_{\mathrm{W}}\left(\mathrm{mmol} \mathrm{g}^{-1}\right)$ & $A_{\mathrm{M}}\left(\mathrm{mmol} \mathrm{g}^{-1}\right)$ & 0.07 \\
CLT & 0.62 & 0.03 & 0.38 & 0.53 \\
AT-CLT & 2.29 & 1.43 & 0.32 & 0.48 \\
Beta & 1.16 & 0.44 & 0.25 & 0.39 \\
Beta/CLT & 1.67 & 1.09 & 0.32 & 0.42 \\
Beta/AT-CLT & 1.89 & 1.15 & 0.23 & 0.34 \\
US-Beta/AT-CLT & 1.70 & 1.14 & $\left.\mathrm{mmol} \mathrm{g}^{-1}\right)$
\end{tabular}

${ }^{a} \mathrm{~A}_{\mathrm{T}}$ : Total acidity. $\mathrm{A}_{\mathrm{M}}$ : Medium acidity. $\mathrm{A}_{\mathrm{W}}$ : Weak acidity. $\mathrm{A}_{\mathrm{S}}$ : Strong acidity.

a certain time on stream, which means gradual increment of liquid product yield occurs. ${ }^{43}$ Finally, gas or liquid product yield reaches a constant value with no further changes, which means deactivation of the catalyst has happened. Ascending trend of liquid product yield over different prepared samples in 300 minutes time on stream is shown in Fig. 8. Beta sample shows increasing values of liquid product until the end of 5 hour time on stream, which indicates on the activity of catalyst. US-Beta/ AT-CLT has also exhibited prolonged activity with increasing value of liquid product until the end of the $5 \mathrm{~h}$ time on stream. High mesoporous volume and external surface area of these samples leads to unlimited mass transfer and reduces pore blockage due to the coke deposition. These results is compatible with results of Oruji et al. ${ }^{43}$ which concluded that catalysts with higher mesopore volumes had higher life times.

Amount of liquid production on Beta/CLT and Beta/AT-CLT has reached to an approximately constant value after 270 minutes, which could be due to the lower mesoporous volume of these samples. CLT and AT-CLT with lowest mesoporosities among all the samples have reached their maximum values after around 240 minutes time on stream.

Gas, liquid and coke products yields and physical properties of liquid products of heavy oil upgrading process are presented in Table 5. Conversion of heavy oil feed during the catalytic

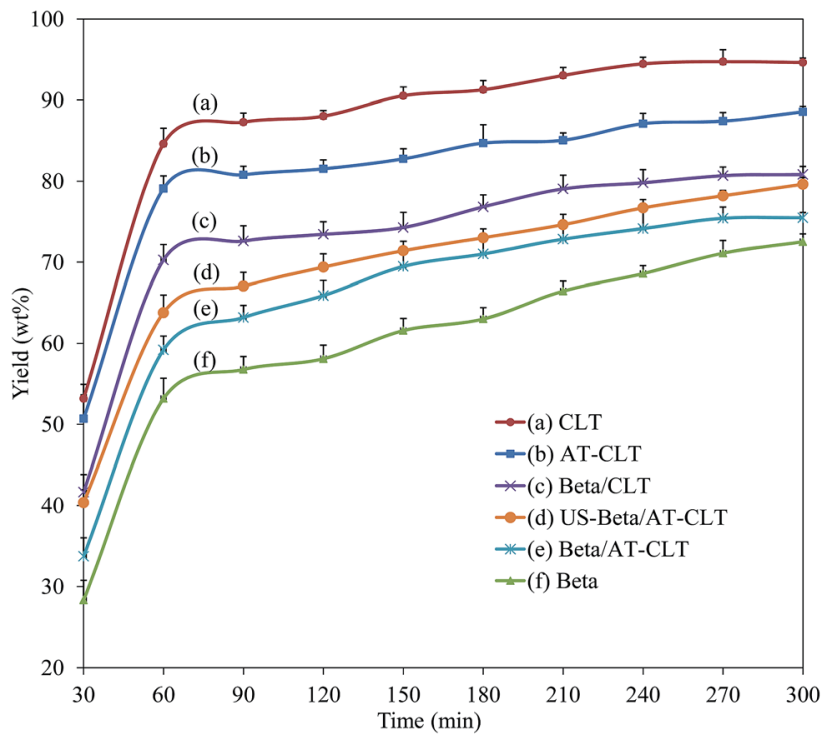

Fig. 8 Liquid product yield as a function of time on stream for prepared samples (reaction conditions: temperature $=550{ }^{\circ} \mathrm{C}$, pressure $=1 \mathrm{~atm}$ and TOS $=300 \mathrm{~min}$ ). cracking is companied by production of gaseous products over catalytic active sites. Higher amount of gas production indicates on higher activity of acidic sites of the catalyst. Maximum gas yield was obtained over Beta and minimum gas yield occurred on CLT sample. Alkaline treatment and creation of larger mesoporous structure as well as increased acidity led to increase in the gas yield over AT-CLT sample. Compared to CLT, amount of gaseous products increased by $40 \%$ over AT-CLT. The same result was observed by Oruji et al. ${ }^{43}$ after performing alkaline treatment on $\mathrm{Y}$ zeolite, where gas production and catalyst activity increased upon inducing mesopores in $\mathrm{Y}$ zeolite through alkaline treatment.

Beta/CLT composite yielded $27.7 \mathrm{wt} \%$ gaseous products, which is two times larger than amount of gas yield on CLT sample (13.2 wt\%). Presence of $30 \mathrm{wt} \%$ Beta in the composite and higher mesoporous structure along with higher total acidity increase the catalyst activity. It should be noticed that amount of gaseous products obtained over this composite is higher than sum of gas produced over each phase individually. In another words there is a synergetic effect between two phases, which results in higher activity. Induced mesopores in the composite structure originating from Beta, facilitate the diffusion of hydrocarbon molecules into clinoptilolite micropores, where strong acid sites are located and more cracking reactions occur.

Beta/AT-CLT has produced higher amount of gaseous products with $32.3 \mathrm{wt} \%$. US-Beta/AT-CLT sample yielded partially lower gas product with $30.5 \mathrm{wt} \%$. Although, largest amount of mesopore volume and surface areas were induced in this sample due to the sonication, higher acidity of Beta/AT-CLT resulted in partially higher activity of the later. These results are in line with result of Zhou et al..$^{54}$ as well as Plana-Pallejà et al. ${ }^{58}$ who concluded that optimal catalytic performance is dependent on tuned structural properties and acidity of the zeolite.

3.2.2. Liquid product specifications. Average viscosities, densities and refractive indexes of prepared samples are presented in Table 5. All the samples have shown lower values for these properties compared to the feed (feed properties are presented in Table 1). Based on the results, Beta sample has decreased the viscosity by $77.2 \%$. CLT has performed weakly upon decreasing viscosity, however, ammonia desorption analysis reveal that high amount of strong acidity is present on CLT surface. Microporous structure and small mesopore volume and surface area restrict the diffusion and accessibility to acidic sites, which weakens the catalytic performance. ${ }^{59}$ ATCLT owns more mesoporous structure with increased diffusion and mass transfer ability as well as much more weak and 
Table 5 Data obtained from catalytic cracking of heavy oil feed over prepared samples

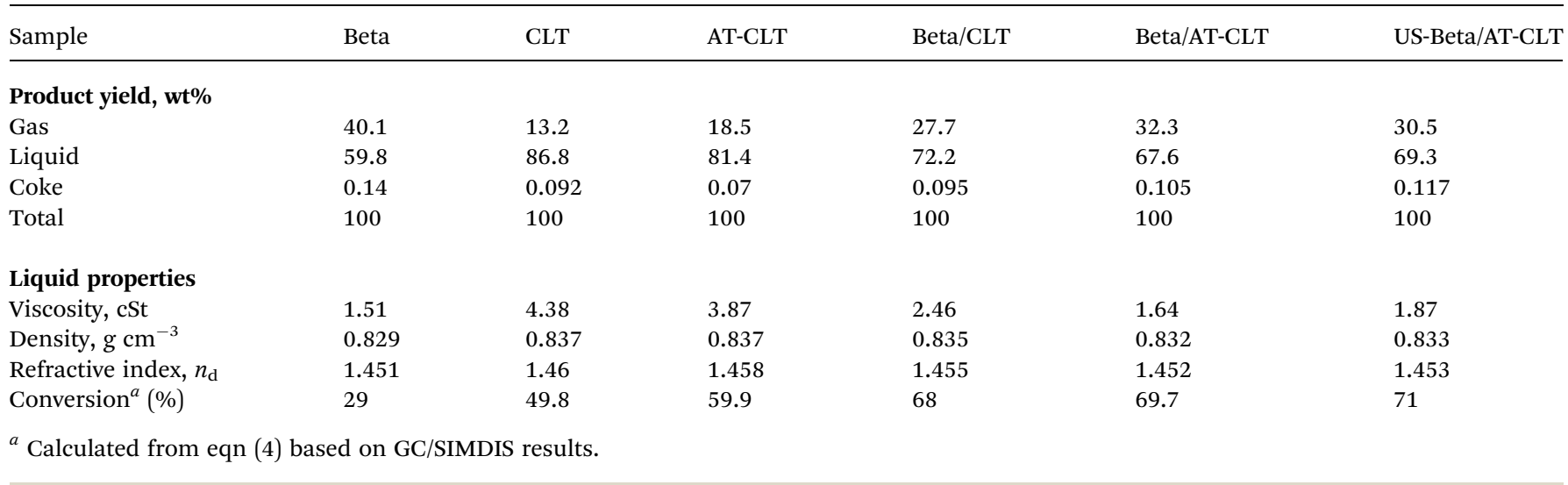

medium acidic sites produced after alkaline treatment. These properties resulted in higher activity of this sample compared to CLT sample and more reduction in feed viscosity, which is an index of lighter hydrocarbons production. ${ }^{43,60}$ Beta/AT-CLT sample has remarkably reduced the viscosity of liquid product by $75.3 \%$, which is nearly similar to Beta sample. Due to the high amount of moderate and weak acidity coupled with improved structural properties, it has shown a nearly equal decrease of viscosity by using only $30 \mathrm{wt} \%$ of Beta sample in beta-clinoptilolite composite. Catalytic performance is a result of synergetic effect of optimized acidity and mesoporous structure with high external surface. Therefore, a combination of adequate porosity and optimized acidity results in the best performance in producing lighter hydrocarbons in liquid product. ${ }^{58}$ Alkaline treatment of CLT produced large number of weak acid sites. The combination of high total acidity of AT-CLT and high mesoporosity of Beta along with moderate acidic sites of the latter is the key to satisfactory performance of the prepared composite. Beta sample possesses moderate, weak and strong acid sites and great degree of mesoporosity, but Beta/AT-CLT composite possess adequate mesoporosity coupled with higher total acidity originated from AT-CLT compared to Beta. Therefore applying only $30 \mathrm{wt} \%$ of beta zeolite in a composite with clinoptilolite ended to have a similar result with pure beta zeolite. Synergetic effect of optimized acidity and mesoporosity brought together is responsible for this achievement.

US-Beta/AT-CLT sample has higher amount of mesopore volume and external surface compared to Beta/AT-CLT sample but slight decrease in acidity and crystallinity has resulted in less catalytic activity and viscosity reduction. ${ }^{13}$ Densities and refractive indexes have decreased over the samples by similar order as viscosity.

Liquid products and feed were also analyzed by SIMDIS GC in order to determine the boiling point distribution and were divided into three different cuts: naphtha + kerosene (30-250 $\left.{ }^{\circ} \mathrm{C}\right)$, diesel $\left(250-370{ }^{\circ} \mathrm{C}\right)$ and heavy oil $\left(370{ }^{\circ} \mathrm{C}+\right)$. Amount of conversion over each sample, calculated from eqn (4), is presented in Table 5.

As shown in Fig. 9, it is revealed that the feed used in this process is mostly composed of heavy hydrocarbons with
$97.8 \mathrm{wt} \%$ of $370{ }^{\circ} \mathrm{C}+$ cut. Amount of diesel cut and naphtha + kerosene cut in the feed were $2.8 \mathrm{wt} \%$ and $0.005 \mathrm{wt} \%$ respectively. Catalytic cracking over CLT with $29 \%$ conversion has increased these cuts to $28.54 \mathrm{wt} \%$ and $2.3 \mathrm{wt} \%$ which was the lowest conversion achieved among all the samples. On the other hand, Beta sample has predictably yielded the highest amount of light cuts with $71 \%$ conversion and $35.58 \mathrm{wt} \%$ naphtha + kerosene and $35.72 \mathrm{wt} \%$ of diesel cut.

Performing alkaline treatment on CLT sample has influenced the liquid product content and has increased naphtha + kerosene cut from $2.3 \mathrm{wt} \%$ to $8.32 \mathrm{wt} \%$ and diesel range hydrocarbons have increased to $42.61 \mathrm{wt} \%$ from $28.54 \mathrm{wt} \%$ on CLT.

Mixing beta zeolite with clinoptilolite has resulted in much more production of light hydrocarbons as can be seen for composite samples. Beta/AT-CLT has shown a remarkable performance in production of lighter hydrocarbons, very close to Beta sample. Production of $33.51 \mathrm{wt} \%$ naphtha + kerosene range hydrocarbons and $69.7 \%$ conversion compared to Beta sample is quite satisfactory. Results for US-Beta/AT-CLT sample are quite similar with minor decrease in conversion, which could be attributed to lower acidity compared to Beta/AT-CLT

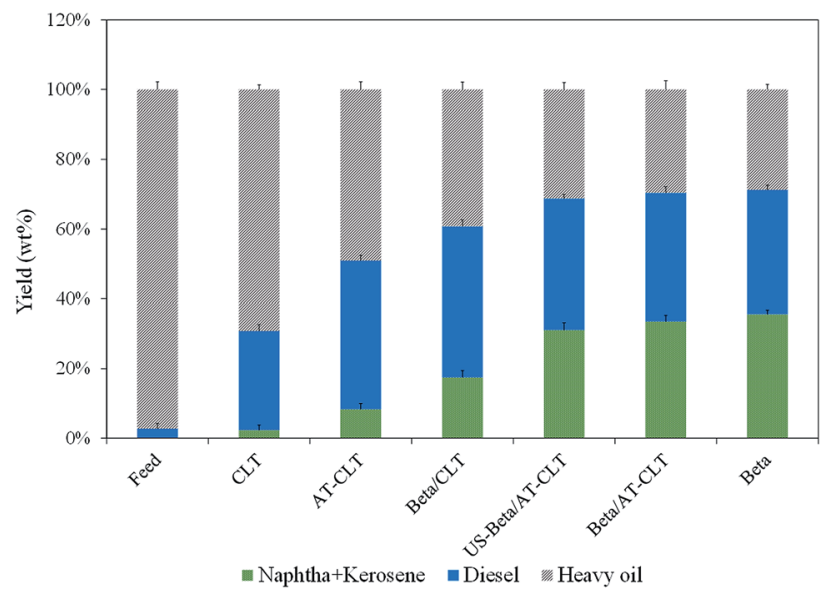

Fig. 9 Boiling point distribution of feed and products of different prepared catalysts (reaction conditions: temperature $=550{ }^{\circ} \mathrm{C}$, pressure $=1 \mathrm{~atm}$ and TOS $=300 \mathrm{~min}$ ). 
sample. These results are also in line with values of liquid physical properties displayed in Table 5. Conversion of high boiling point hydrocarbons present in feed, to lighter hydrocarbons leads to the formation of products with lower viscosities.

Bulky molecules of heavy hydrocarbons fail to enter the micropores with small openings, where acidic sites are located. Mesoporosity increases diffusion and mass transfer rate in zeolite pore structure, resulting in more efficient cracking performance toward higher hydrocarbons. Results obtained from heavy oil upgrading process reveal that synergetic effect of optimized acidity and mesoporous structure induced in the composite has improved catalytic performance of $30 \mathrm{wt} \%$ Beta/ AT-CLT and US-Beta/AT-CLT to a comparable level to the Beta sample.

Liquid products were also explored by GC/MS analysis to determine the PONA distribution of naphtha + kerosene fraction produced over the catalysts. Since viscosity reduction and conversion on CLT and AT-CLT samples were low, GC/MS analysis was only performed on the products of Beta and three composite samples, which resulted more comparable conversions. Based on the results presented in Table 6, it was revealed that amount of paraffins, olefins, naphthenes and aromatics in the produced naphtha + kerosene fraction is different for each sample depending on the pore structure and acidity properties of catalyst in spite of similar degree of conversion. Amount of paraffin produced over different samples does not change remarkably but yield of aromatics and olefins and naphthenes have noticeable differences.

According to the literature, strong Brønsted acidic sites are responsible of hydrogen transfer reactions and aromatic production. ${ }^{\mathbf{5 4 , 6 1}}$ With optimized amount of acidity, naphthenes and olefins have the possibility to convert to aromatics and paraffins according to the general reaction: ${ }^{43}$

$$
\text { Naphthenes }+ \text { olefins } \rightarrow \text { aromatics }+ \text { paraffins }
$$

This conversion could be attributed to the hydrogen transfer ability of the catalyst, which is a function of acidity and mesoporosity. Beta sample has produced highest amount of paraffinic and aromatic hydrocarbons due to the high acidity and mesoporous structure, which facilitates diffusion through the micropores. Minimum amount of aromatic production has occurred for Beta/CLT sample. Conducting alkali treatment has increased aromatic production from $37.4 \%$ over Beta/CLT composite to $54.9 \%$ over Beta/AT-CLT sample due to the

Table 6 PONA Hydrocarbon distribution of naphtha + kerosene cut produced over prepared samples

\begin{tabular}{lllll}
\hline & \multicolumn{2}{l}{ Catalyst sample } & & \\
\cline { 2 - 5 } PONA yield (wt\%) & Paraffin & Olefin & Naphthene & Aromatic \\
\hline Beta & 5.6 & 24.5 & 0.98 & 68.9 \\
Beta/CLT & 4.3 & 48.1 & 10.2 & 37.4 \\
Beta/AT-CLT & 4.5 & 36.6 & 4.8 & 54.9 \\
US-Beta/AT-CLT & 4.2 & 38.6 & 12.9 & 44.3
\end{tabular}

improved mass transfer inside the pores as well as acidity. Ultrasound irradiated sample has shown lower improvement in aromatic production due to the lower acidity compared to Beta/ AT-CLT sample.

Plana et al. ${ }^{58}$ observed same results in their research on the effect of catalyst properties on hydrocarbon distribution in the product, during Fischer-Tropsch synthesis (FTS). Based on their results higher aromatic production occurs over the sample with highest acidity. It has been demonstrated ${ }^{58}$ that aromatization occurs in both the external acid sites and in Brønsted acid sites located inside the micropores (with diffusion constraints). Therefore, Beta/AT-CLT sample shows close performance to Beta sample, since it has a lot of surface acidity induced after alkaline treatment.

3.2.3. Coke product specification. Amount of coke produced on each catalyst was assessed by TGA analysis after $5 \mathrm{~h}$ process plus 1 hour purging with nitrogen and is presented in Table 5. Minimum coke deposition was observed on AT-CLT sample. This is consistent with results of Li et al. ${ }^{62}$ and Gao et al. ${ }^{63}$ who observed lower coke formation over alkaline treated HZSM-5 in olefin aromatization process. They revealed that introduction of mesopores to zeolite structure by desilication can shorten the diffusion path of feed/product resulting in lower residence time of hydrocarbon molecules on active sites. They concluded that mesopores are preferable for coke precursors diffusing out of pore channels.

Alkaline treatment has decreased the amount of coke formation on AT-CLT due to the increased mesopore volume and external surface area compared to CLT. The highest amount of coke was deposited over Beta sample due to the higher degree of catalytic activity and high amount of aromatics produced over this sample.

Beta/AT-CLT and US-Beta/AT-CLT sample exhibited lower coke production compared to Beta while resulted similar degree of conversion.

Coke produced over the samples was also examined by FTIR analysis. Fig. 10 shows FTIR spectra recorded for all the prepared samples. The main characteristic bands of clinoptilolite are at the regions of $4000-3000 \mathrm{~cm}^{-1}$ and $1900-400 \mathrm{~cm}^{-1}$ in which, observed peak at $467 \mathrm{~cm}^{-1}$ is related to the vibration of $\mathrm{Al}-\mathrm{O}$ bands and the one at $612 \mathrm{~cm}^{-1}$ is ascribed to the external linkage of tetrahedral. Characteristic peaks observed at $792 \mathrm{~cm}^{-1}$ and $1079 \mathrm{~cm}^{-1}$ belong to the vibration of $\mathrm{Si}-\mathrm{O}-\mathrm{Si}$ bands (asymmetric and symmetric vibrations of T-O-T) and existence of characteristic peak at $3644 \mathrm{~cm}^{-1}(3400$ and $3800 \mathrm{~cm}^{-1}$ ) represents hydroxyl presence. ${ }^{\mathbf{1 4 , 1 7 , 6 4}}$

FTIR spectra of Beta sample shows characteristic peaks of beta zeolite. Peaks at $522 \mathrm{~cm}^{-1}$ and $574 \mathrm{~cm}^{-1}$ are due to the presence of five-six membered rings and peak around $1087 \mathrm{~cm}^{-1}$ is related to asymmetric O-T-O stretching vibration which is related to $\mathrm{Si} / \mathrm{Al}$ ratio of the framework. ${ }^{65}$

Based on the literature the bands located in $1300-1700 \mathrm{~cm}^{-1}$ region are assigned to unsaturated carbonaceous components deposited on the catalyst. ${ }^{\mathbf{4 3 , 6 6}}$ Peaks around $1600 \mathrm{~cm}^{-1}$ observed in all the samples, are attributed to the stretching vibrations of $\mathrm{C}=\mathrm{C}$ band in the aromatic rings. ${ }^{67}$ Peak observed at $1583 \mathrm{~cm}^{-1}$ for Beta sample is corresponded to polycondensed aromatic 


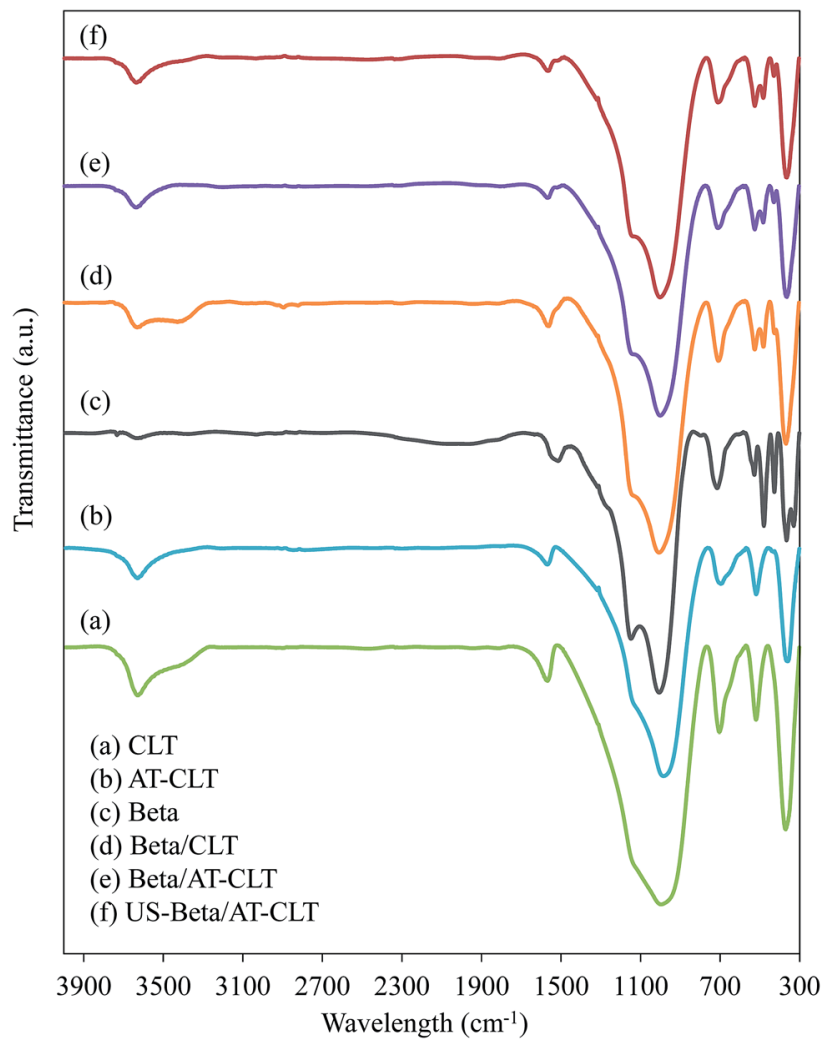

Fig. 10 FTIR spectra of spent samples: (a) CLT, (b) AT-CLT, (c) Beta, (d) Beta/CLT, (e) Beta/AT-CLT, (f) US-Beta/AT-CLT (reaction conditions: temperature $=550{ }^{\circ} \mathrm{C}$, pressure $=1 \mathrm{~atm}$ and $\mathrm{TOS}=300 \mathrm{~min}$ ).

coke and peak observed at $1635 \mathrm{~cm}^{-1}$ for CLT and AT-CLT samples could be attributed to the conjugated olefin coke according to the previous reports. ${ }^{43,66,68}$ This is also in line with GC-Mass results, which revealed that aromatic compounds were dominating products over Beta sample while composites of beta and clinoptilolite resulted in production of more olefin compounds compared to Beta. Beta/CLT, Beta/AT-CLT and USBeta/AT-CLT samples represent shifted peaks at $1630 \mathrm{~cm}^{-1}$, which is explained by more olefins produced on these samples compared to Beta sample.

Bands located in $2800-3100 \mathrm{~cm}^{-1}$ region, are related to stretching vibrations of aliphatic coke, ${ }^{66-68}$ and the band at $1558 \mathrm{~cm}^{-1}$ is assigned to the stretching vibration of $\mathrm{C}=\mathrm{C}$ band in microcrystalline graphitic carbon structures which none of them are observed for prepared samples as can be seen in Fig. $10 .{ }^{43}$ In addition, bands at $3000-3400 \mathrm{~cm}^{-1}$ are assigned to weak $\mathrm{C}-\mathrm{H}$ stretching vibration corresponded to aromatic groups and absence of these peaks reveals that aromatic groups deposited on these catalysts have low content of hydrogen. ${ }^{67}$

3.2.4. Spent catalyst specification. The structural stability of prepared samples during the catalytic cracking reaction was examined by XRD analysis. After the reaction, spent catalysts were calcinated in air stream at $550{ }^{\circ} \mathrm{C}$ for $4 \mathrm{~h}$ in order to burn the deposited coke. The X-ray diffraction patterns for all the six samples are presented in Fig. 11. All the samples have preserved their crystallinity and show related diffraction peaks, however, with lower intensities compared to the fresh ones. Table 2 presents the calculated relative crystallinities of the spent samples along with the related results for the fresh ones. Beta sample shows great stability after 5 hour time on stream. CLT and AT-CLT samples have lost their crystallinity during the process by $17.2 \%$ and $23.4 \%$ respectively.

Among the prepared composites, US-Beta/AT-CLT shows the minimum decrease in crystallinity, which means that ultrasound irradiation has improved the stability of prepared composite structure. Khoshbin et al. ${ }^{49}$ also studied the spent ZSM-5 catalysts modified with sonication and concluded that ultrasound irradiation increased the stability of catalyst compared to conventional modification. Larger external surface area of sonicated sample could be the reason of higher stability compared to conventionally mixed composite. Higher external surface area leads to formation of higher number of pore openings inhibiting the pore blockage. In other words, increment in number of pore openings reduces the likelihood of pore plugging and deactivation of catalyst. Sene et al. ${ }^{39}$ also demonstrated that formation of microjets after bubble implosions near the surface of the particles, cause high-velocity interparticle collisions in solid-liquid system resulting in more stable positioning of particles on the clinoptilolite surface in the mixture..$^{39}$

This evaluation reveals that although Beta/AT-CLT sample shows slightly better cracking performance toward production

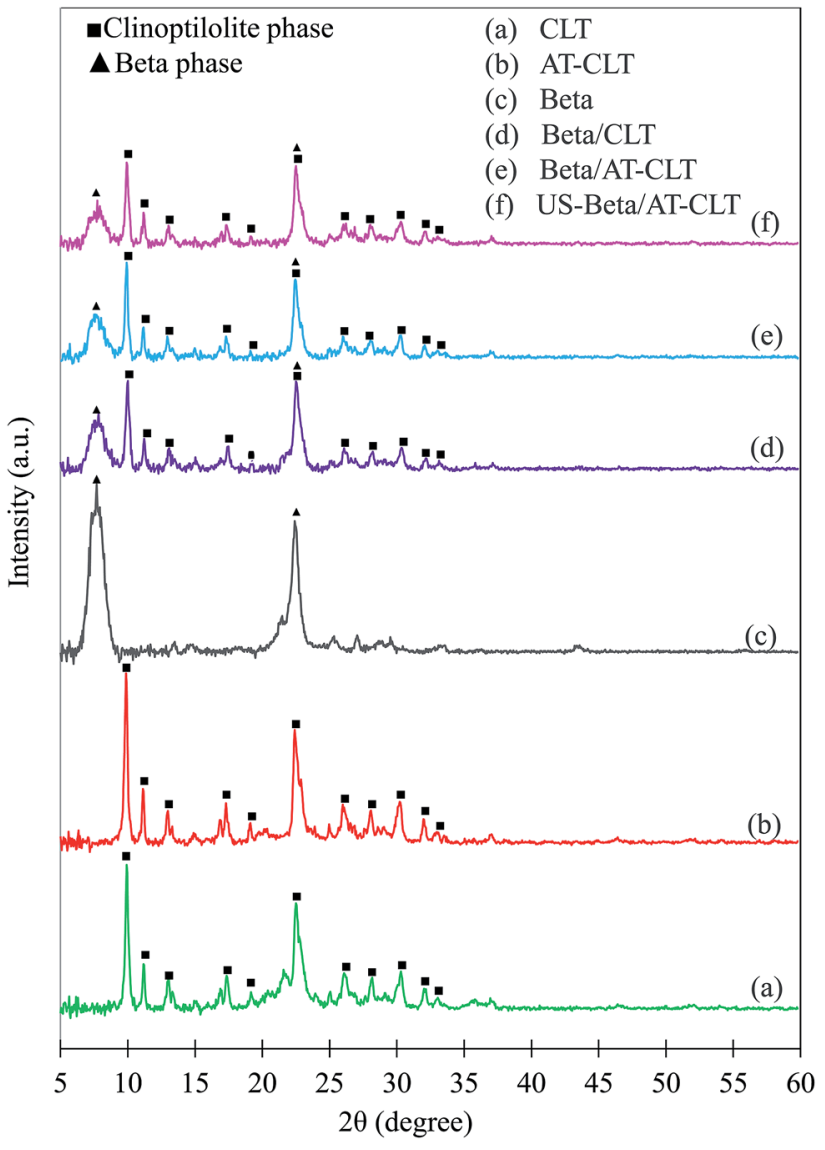

Fig. 11 XRD patterns of calcinated spent catalysts: (a) CLT, (b) AT-CLT, (c) Beta, (d) Beta/CLT, (e) Beta/AT-CLT, (f) US-Beta/AT-CLT ( $\Delta$ Beta phase, clinoptilolite phase). 
of lighter hydrocarbons, US-Beta/AT-CLT exhibits more stability in cracking reaction after $5 \mathrm{~h}$ time on stream and is more suitable for regeneration and further utilizations.

\section{Conclusions}

Physical composites of beta zeolite and treated clinoptilolite samples were prepared by conventional and sonicated mixing procedures. XRD analysis proved the presence of both zeolitic phases in the composites while preserving crystalline structure. Results revealed that alkaline treatment of clinoptilolite zeolite increased mesopore volume and total acidity of this sample. Preparing $30 \mathrm{wt} \%$ composites of beta with clinoptilolite samples also resulted in improved mesoporosity and acidity based on BET and $\mathrm{NH}_{3}$-TPD analyses. Prepared samples were examined in heavy oil upgrading process and the highest amount of light hydrocarbon production occurred on beta zeolite predictably, although composite of beta and alkali treated clinoptilolite exhibited very similar results to pure beta sample in viscosity reduction and lighter hydrocarbon production, while producing lower amount of coke compared to beta zeolite. Preparing composite under ultrasound irradiation remarkably increased the structural stability of the composite after $5 \mathrm{~h}$ time on stream.

$30 \mathrm{wt} \%$ beta-clinoptilolite physical composite prepared in this study exhibited comparable cracking performance to pure beta zeolite and noticeable structural stability. Obtaining these results is satisfactory since development of modification processes, which improve catalytic performance and structural stability of natural zeolite is economically desirable, especially for heavy oil upgrading processes with massive catalyst consumptions.

\section{Conflicts of interest}

There are no conflicts to declare.

\section{References}

1 B. Sarkar, W. Kwek, D. Verma and J. Kim, Appl. Catal., A, 2017, 545, 148-158.

2 M. Ghashghaee and S. Shirvani, Ind. Eng. Chem. Res., 2018, 57, 7421-7430.

3 A. Demirbas, A. Bafail and A.-S. Nizami, Pet. Sci. Technol., 2016, 34, 303-308.

4 M. S. Rana, V. Sámano, J. Ancheyta and J. A. I. Diaz, Fuel, 2007, 86, 1216-1231.

5 B. Roozbehani, M. Motevassel, M. Mirdrikvand, S. I. Moqadam and A. Kharaghani, Clean Technol. Environ. Policy, 2017, 19, 123-136.

6 A. C. F. Coriolano, A. A. A. Oliveira, R. A. F. Bandeira, V. J. Fernandes and A. S. Araujo, J. Therm. Anal. Calorim., 2015, 119, 2151-2157.

7 A. AfsharEbrahimi and S. Tarighi, Pet. Sci. Technol., 2015, 33, 415-421.

8 S.-C. Baek, Y.-J. Lee, K.-W. Jun and S. B. Hong, Energy Fuels, 2009, 23, 593-598.
9 A. S. M. Junaid, H. Yin, A. Koenig, P. Swenson, J. Chowdhury, G. Burland, W. C. McCaffrey and S. M. Kuznicki, Appl. Catal., A, 2009, 354, 44-49.

10 X. Fu, X. Sheng, Y. Zhou, Z. Fu, S. Zhao, X. Bu and C. Zhang, RSC Adv., 2016, 6, 50630-50639.

11 F. Gorzin, J. Towfighi Darian, F. Yaripour and S. M. Mousavi, RSC Adv., 2018, 8, 41131-41142.

12 L. Zhao, J. Gao, C. Xu and B. Shen, Fuel Process. Technol., 2011, 92, 414-420.

13 K. Tarach, K. Góra-Marek, J. Tekla, K. Brylewska, J. Datka, K. Mlekodaj, W. Makowski, M. C. Igualada López, J. Martínez Triguero and F. Rey, J. Catal., 2014, 312, 46-57.

14 M. Moradi, R. Karimzadeh and E. S. Moosavi, Fuel, 2018, 217, 467-477.

15 H. Sun, P. Peng, Y. Wang, C. Li, F. Subhan, P. Bai, W. Xing, Z. Zhang, Z. Liu and Z. Yan, J. Porous Mater., 2017, 24, 15131525.

16 A. Dziedzicka, B. Sulikowski and M. Ruggiero-Mikołajczyk, Catal. Today, 2016, 259, 50-58.

17 H. Lin, Q.-l. Liu, Y.-b. Dong, Y.-h. He and L. Wang, Microporous Mesoporous Mater., 2015, 218, 174-179.

18 W. Ma, B. Liu, X. Ji, X. Li, B. Yan, Z. Cheng and G. Chen, Biomass Bioenergy, 2017, 102, 31-36.

19 A. A. Ebrahimi, S. Tarighi and A. B. Ani, Kinet. Catal., 2016, 57, 610-616.

20 Y. Li, W. Zhang, X. Wang, Y. Zhang, T. Dou and K. Xie, J. Porous Mater., 2008, 15, 133-138.

21 J. Zheng, X. Zhang, Y. Wang, Y. Bai, W. Sun and R. Li, J. Porous Mater., 2008, 16, 731.

22 Y. Zhao, X. Zhao, J. Deng and C. He, J. Radioanal. Nucl. Chem., 2016, 308, 701-709.

23 P. G. Smirniotis and E. Ruckenstein, Ind. Eng. Chem. Res., 1994, 33, 800-813.

24 U. Khalil, O. Muraza, H. Kondoh, G. Watanabe, Y. Nakasaka, A. Al-Amer and T. Masuda, Energy Fuels, 2016, 30, 1304-1309.

25 Z. Liu, L. Zhao, T. Zhang, Y. Wang, Y. Xu, S. Komarneni, Y. Wang, X. Liu and Z. Yan, J. Porous Mater., 2018, DOI: 10.1007/s10934-018-0697-x.

26 X. Zhang, Q. Guo, B. Qin, Z. Zhang, F. Ling, W. Sun and R. Li, Catal. Today, 2010, 149, 212-217.

27 B. Ren, S. Bai, J. Sun, F. Zhang and M. Fan, RSC Adv., 2014, 4, 22755-22758.

28 Y.-S. Ooi, R. Zakaria, A. R. Mohamed and S. Bhatia, Appl. Catal., A, 2004, 274, 15-23.

29 A. Duan, C. Wang, Z. Zhao, Z. Tong, T. Li, H. Wu, H. Fan, G. Jiang and J. Liu, J. Porous Mater., 2013, 20, 1195-1204.

30 L. Gao, Z. Shi, U. J. Etim, P. Wu, D. Han, W. Xing, S. Mintova, P. Bai and Z. Yan, Microporous Mesoporous Mater., 2019, 277, 17-28.

31 H. He, B. Wu and C. Yang, Int. J. Environ. Sci. Technol., 2018, DOI: $10.1007 / \mathrm{s} 13762-018-2148-2$.

32 H. He, Y. Cheng, C. Yang, G. Zeng, C. Zhu and Z. Yan, J. Environ. Sci., 2017, 54, 135-141.

33 M. Faryadi, M. Rahimi, S. Safari and N. Moradi, Chem. Eng. Process., 2014, 77, 13-21.

34 R. Khoshbin and R. Karimzadeh, Adv. Powder Technol., 2017, 28, 1888-1897. 
35 S. Bennici, A. Gervasini and V. Ragaini, Ultrason. Sonochem., 2003, 10, 61-64.

36 L. Belaya, V. Doronin and T. Sorokina, Catalysis in Industry, 2009, 1, 237-242.

37 H. Liu, S. Zhang, Y. Zhou, Y. Zhang, L. Bai and L. Huang, Ultrason. Sonochem., 2011, 18, 19-22.

38 Y. Vafaeian, M. Haghighi and S. Aghamohammadi, Energy Convers. Manage., 2013, 76, 1093-1103.

39 R. Akbari Sene, G. R. Moradi and S. Sharifnia, Ultrason. Sonochem., 2017, 37, 490-501.

40 C. Ma, J. Yu, Q. Yan, Z. Song, K. Wang, B. Wang and L. Sun, Polym. Degrad. Stab., 2017, 146, 1-12.

41 A. Ates and C. Hardacre, J. Colloid Interface Sci., 2012, 372, 130-140.

42 S. Asadi, L. Vafi and R. Karimzadeh, Microporous Mesoporous Mater., 2018, 255, 253-260.

43 S. Oruji, R. Khoshbin and R. Karimzadeh, Fuel Process. Technol., 2018, 176, 283-295.

44 R. A. Sene, S. Sharifnia and G. R. Moradi, Int. J. Hydrogen Energy, 2018, 43, 695-707.

45 F. Rahmani, M. Haghighi and S. Mahboob, Ultrason. Sonochem., 2016, 33, 150-163.

46 M. Rahimi, S. Safari, M. Faryadi and N. Moradi, Chem. Eng. Process., 2014, 78, 17-26.

47 M. Akgül and A. Karabakan, Microporous Mesoporous Mater., 2011, 145, 157-164.

48 C. Wang, S. Leng, H. Guo, L. Cao and J. Huang, Appl. Surf. Sci., 2019, 478, 319-326.

49 R. Khoshbin and R. Karimzadeh, Adv. Powder Technol., 2017, 28, 973-982.

50 T. De Baerdemaeker, B. Yilmaz, U. Müller, M. Feyen, F.-S. Xiao, W. Zhang, T. Tatsumi, H. Gies, X. Bao and D. De Vos, J. Catal., 2013, 308, 73-81.

51 L. I. Gurevich Messina, P. R. Bonelli and A. L. Cukierman, Fuel Process. Technol., 2017, 159, 160-167.
52 D. Verboekend, T. C. Keller, M. Milina, R. Hauert and J. Pérez-Ramírez, Chem. Mater., 2013, 25, 1947-1959.

53 S. Allahyari, M. Haghighi, A. Ebadi and S. Hosseinzadeh, Ultrason. Sonochem., 2014, 21, 663-673.

54 F. Zhou, Y. Gao, G. Wu, F. Ma and C. Liu, Microporous Mesoporous Mater., 2017, 240, 96-107.

55 A. Ghahri, F. Golbabaei, L. Vafajoo, S. M. Mireskandari, M. Yaseri and S. J. Shahtaheri, Int. J. Environ. Res., 2017, 11, 327-337.

56 J. Li, X. Li, G. Zhou, W. Wang, C. Wang, S. Komarneni and Y. Wang, Appl. Catal., A, 2014, 470, 115-122.

57 T. E. Tshabalala and M. S. Scurrell, Catal. Commun., 2015, 72, 49-52.

58 J. Plana-Pallejà, S. Abelló, C. Berrueco and D. Montané, Appl. Catal., A, 2016, 515, 126-135.

59 A. Feliczak-Guzik, Microporous Mesoporous Mater., 2018, 259, 33-45.

60 R. Asgharzadeh Shishavan, M. Ghashghaee and R. Karimzadeh, Fuel Process. Technol., 2011, 92, 2226-2234.

61 E. E. Kolesnikova, T. K. Obukhova, N. V. Kolesnichenko, G. N. Bondarenko, O. V. Arapova and S. N. Khadzhiev, Pet. Chem., 2018, 58, 863-868.

62 Y. Li, S. Liu, S. Xie and L. Xu, Appl. Catal., A, 2009, 360, 8-16. 63 X. Gao, Z. Tang, G. Lu, G. Cao, D. Li and Z. Tan, Solid State Sci., 2010, 12, 1278-1282.

64 E. Moradiyan, R. Halladj, S. Askari and P. Moghimpour Bijani, J. Phys. Chem. Solids, 2017, 107, 83-92.

$65 \mathrm{~J}$. Li, H. Liu, T. An, Y. Yue and X. Bao, RSC Adv., 2017, 7, 33714-33725.

66 S. Abbasizadeh and R. Karimzadeh, Ind. Eng. Chem. Res., 2018, 57, 7783-7794.

67 H. Zhang, S. Shao, R. Xiao, D. Shen and J. Zeng, Energy Fuels, 2014, 28, 52-57.

68 A. T. Aguayo, P. Castaño, D. Mier, A. G. Gayubo, M. Olazar and J. Bilbao, Ind. Eng. Chem. Res., 2011, 50, 9980-9988. 